\title{
Effects of chronic consumption of energy drinks on liver and kidney of experimental rats
}

\author{
Wael Mansy ${ }^{1,2 \star}$, Deema M Alogaiel ${ }^{3}$, Mona Hanafi ${ }^{4}$, Enas Zakaria ${ }^{5}$ \\ ${ }^{1}$ Clinical Pharmacy Department, College of Pharmacy, King Saud University, Riyadh, Saudi Arabia, ${ }^{2}$ Pharmacology \\ Department, Faculty of Medicine, Cairo University, Cairo, Egypt, ${ }^{3}$ Health Sciences Department, College of Health and \\ Rehabilitation, Princess Nourah Bint Abdulrahman University, ${ }^{4}$ Department of Community Health Sciences. College of Applied \\ Medical Sciences, ${ }^{5}$ Pharmaceutics Department, College of Pharmacy, King Saud University, Riyadh, Saudi Arabia
}

*For correspondence: Email: whsayed@hotmail.com; Tel: +966567253275

\begin{abstract}
Purpose: To investigate the effects of chronic intake of a brand of energy drink (ED) on the liver and kidney of rats.

Methods: Sixty male adult Sprague Dawley albino rats were randomly assigned to four groups (15 rats per group). Three groups received ED at different doses (0.4, 1.1 and $2.2 \mathrm{ml} / 100 \mathrm{~g}$ body weight/day) for 12 weeks. The fourth group (control) received distilled water. All treatments were administered by oral gavage. Blood samples were withdrawn at the start of the experiment, and at the 6th and 12th weeks for assay of hepatic and renal biochemical parameters. Histopathological studies were done at the end of the exposure period.

Results: Exposure to ED doses of 1.1 and $2.2 \mathrm{ml} / 100 \mathrm{~g}$ body weight/day for 12 weeks induced highly significant increases in serum aspartate transaminase (AST), alanine transaminase (ALT), alkaline phosphatase $(A L P)$, blood urea nitrogen $(B U N)$, creatinine and uric acid, when compared with the control group $(p<0.001)$. On the other hand, the activities of the antioxidant enzymes, viz, superoxide dismutase (SOD), glutathione peroxidase (GPx) and catalase (CAT) significantly decreased $(p<0.001)$ by exposure to these two ED doses, relative to controls. Pronounced histopathological changes were observed in hepatic and renal tissues of the ED-treated rats.

Conclusion: Oral exposure of rats to ED for 12 weeks produced noticeable hepatic and renal damage, probably due to increased free radical production and oxidative stress.
\end{abstract}

Keywords: Energy drink, Reactive oxygen species, Liver function, Kidney function, Histopathological changes

\begin{abstract}
This is an Open Access article that uses a funding model which does not charge readers or their institutions for access and distributed under the terms of the Creative Commons Attribution License (http://creativecommons.org/licenses/by/4.0) and the Budapest Open Access Initiative (http://www.budapestopenaccessinitiative.org/read), which permit unrestricted use, distribution, and reproduction in any medium, provided the original work is properly credited.

Tropical Journal of Pharmaceutical Research is indexed by Science Citation Index (SciSearch), Scopus, International Pharmaceutical Abstract, Chemical Abstracts, Embase, Index Copernicus, EBSCO, African Index Medicus, JournalSeek, Journal Citation Reports/Science Edition, Directory of Open Access Journals (DOAJ), African Journal Online, Bioline International, Open-J-Gate and Pharmacy Abstracts
\end{abstract}

\section{INTRODUCTION}

First appearance of energy drinks (EDs) was in Europe and Asia in the 1960 as a result of customer requirements for dietary supplements that give energy [1]. Many Saudi studies found that more than half of the consumers were young (13 - 35 years old), more than half consumed it for over a year, and over $40 \%$ used to drink more than 3 cans per week [2]. Centers for Disease Control and Prevention reported that high school students consume 
EDs almost at the same rate as they consume soda [1]. Indeed, the rate of ED consumption might be higher than estimated levels in this self-reporting survey, since such surveys usually have high probability of underestimation.

It has been revealed that EDs contain mainly taurine, glucuronolactone, caffeine, ginseng and guarana [3]. These substances, most of which act as stimulants, are not included in the list of materials under regulation by the Food and Drug Administration (FDA) of the United States of America. The levels of these stimulants vary amongst different brands of EDs, and in most cases, are higher than values allowable [4]. A study has shown that the caffeine levels in EDs are between 50 and 505 $\mathrm{mg} / \mathrm{can}$, which are much higher than the caffeine content of one can of Coke (34 mg) [5].

Reports of significant, adverse health problems due to ingestion of EDs have increased in recent years. Indeed, in 2013, ED-associated emergency interventions by the US Substance Abuse and Mental Health Services Administration doubled from 10,068 in 2017 to over 20,000 in 2011 [6]. A major constraint in understanding the link between EDs and the adverse effects of their consumption is that very little is known about the toxicity of the various compounds present in them. However, based on reported cases of ED-associated health problems, and the well-established physiological effects of the active ingredients of EDs, it is very likely that the observed adverse effects of EDs are linked to their compositions [3]. Due to the aforementioned reasons we purposed this study to explore the toxic effects of prolonged intake of ED on hepatic and renal tissues of rats.

\section{EXPERIMENTAL}

\section{Energy drink}

The brand of ED used in the present study was "Red bull", product of Rauch Trading AG, Switzerland (manufactured for Red Bull GmbH, Austria). It was purchased from a local store in Riyadh, Saudi Arabia.

\section{Animal feeding}

Sixty (60) adult, male Sprague Dawley rats (mean weight $=115.5 \mathrm{~g}$ ) were kept in the Animal House of College of Pharmacy, King Saud University. The rats were acclimatized under a $12 \mathrm{~h} / 12 \mathrm{~h}$ light/dark photoperiod and under normal, healthy laboratory conditions at a mean temperature of $25 \pm 2{ }^{\circ} \mathrm{C}$. The experiments were carried out in line with the recommendations of International Laboratory Animal Use and Care [7]. The study protocols and ethics were approved by the Animal Research and Ethical Committee of King Saud University (approval No. CAMS24/3334, June 2013).

\section{Experimental design}

Four (4) groups of rats were used (15 rats/group). There was no bias in the allocation of rats to any group. Rats in the control group (G1) were maintained on the basal diet and distilled water throughout the experiment. Three levels of ED exposure were used: mild, moderate and high ED. Rats in the mild ED intake group (G2) was given low dose of ED (0.4 $\mathrm{ml} / 100 \mathrm{~g}$ body weight / day) to simulate low human consumption pattern (280 ml/ED can), while the moderate ED group (G3) received $1.1 \mathrm{ml} / 100 \mathrm{~g}$ body weight / day, to reflect moderate human consumption level of $770 \mathrm{ml}$ (about 3 cans of ED). The high ED intake group (G4) was given $2.2 \mathrm{ml} / 100 \mathrm{~g}$ body weight/day to mimic estimated high human consumption level of $1540 \mathrm{ml}$ (about six cans). All treatments were given by gavage, and lasted for 12 weeks.

\section{Sample collection}

Prior to the commencement of ED exposure, blood samples were taken from the retrobulbar venous plexus for the determination of various basal biochemical parameters. Blood samples were also drawn through the same route at the 6 th week (mid-way) and at the end (12th week), for similar assays. The samples were allowed to coagulate and the sera were stored at $-20{ }^{\circ} \mathrm{C}$ prior to assay of AST, ALT, BUN and ALP. Moreover, plasma samples from blood collected in anticoagulant bottles were frozen at $-20^{\circ} \mathrm{C}$ and used for assay of CAT activity. The pellet (erythrocytes) was washed thrice in $3 \mathrm{~mL}$ of physiological saline, and centrifuged for $10 \mathrm{~min}$ at $3000 \times \mathrm{g}$. The erythrocytes were thereafter hemolyzed with 1.5 volume of distilled water, and the hemolysate was clarified by centrifugation for $15 \mathrm{~min}$ at $10,000 \times \mathrm{g}$ and $4{ }^{\circ} \mathrm{C}$. The resultant supernatant was used for the assay of the activities of the antioxidant enzymes GPx and SOD.

\section{Histological examination}

Blood samples were taken at the expiration of week 12, and all rats were sacrificed by decapitation. Liver and kidney samples were immediately excised and processed for light 
microscopy and histological investigation using standard methods. Specimens were fixed in 10 $\%$ neutral formalin and stained with hematoxylin and eosin.

\section{Biochemical analysis}

The activities of ALT, ALP and AST, and the levels of creatinine, BUN and uric acid were measured colorimetrically using Randox UV kinetic method kits (Randox, USA) in line with the manufacturer's protocol [8]. Plasma catalase (CAT) and erythrocyte SOD and GPx activities were also assayed colorimetrically using Randox assay kits (Randox, USA) according to the procedures specified by the kit manufacturer $[9,10]$.

\section{Statistical analysis}

Data are presented as mean \pm SE. One-way analysis of variance (ANOVA) was used for assessing differences among groups. This was followed by Bonferroni post-hoc paired comparison using Windows SPSS version 20.0 (SPSS Inc., Chicago IL, USA). $P<0.05$ was taken as indicating statistically significant differences.

\section{RESULTS}

\section{Liver function}

Rats treated with either moderate or high doses of ED had significant increases in serum AST,
ALT and ALP levels at weeks 6 and 12 of the experimental period, when compared with their baseline levels and corresponding levels in the control group. These results are shown in Tables 1, 2 and 3 below.

\section{Kidney function}

The effects of the three doses of ED on kidney function of rats are presented in Tables 4, 5 and 6. Rats exposed to high doses of ED had significant increases in serum creatinine, BUN and uric acid levels at week 12 when compared with the baseline levels of these parameters, and the corresponding values in the control group.

\section{Activity of antioxidant enzymes}

The effect of the three doses of ED on levels of some antioxidant enzymes in rats are presented in Tables 7, 8 and 9. Exposure to high dose of ED led to significant decreases in SOD, GPx and CAT activities at 12 weeks of the experimental period, relative to their baseline levels and the corresponding levels in the control group.

\section{Histological features}

The general architecture of the liver and the kidneys in G4 were distorted with congestion of central and portal veins and inflammation of portal areas as shown in Figure 1 I. Proliferation of bile ducts and starting fibrosis appears in Figure $1 \mathrm{II}$.

Table 1: Serum AST (U/L) levels of rats treated daily by different concentrations of energy drinks for 12 weeks

\begin{tabular}{lcccc}
\hline \multirow{2}{*}{ Group } & \multicolumn{3}{c}{ Duration of consumption } & \multirow{2}{*}{$\boldsymbol{P}$-value } \\
\cline { 2 - 4 } & Initial & Half-way $(\mathbf{6}$ weeks) & End (12 weeks) & \\
\hline Group 1:(control) & & $68.60 \pm 4.70^{\mathrm{a} 1}$ & $67.77 \pm 3.81^{\mathrm{al}}$ & 0.83 \\
Group 2:(0.4 ml/100g/day) & $66.20 \pm 4.55^{1}$ & $78.21 \pm 4.76^{\mathrm{ab} 12}$ & $91.21 \pm 4.76^{\mathrm{b} 2}$ & 0.001 \\
Group 3:(1.1 ml/100g/day) & & $93.43 \pm 6.91^{\mathrm{b} 2}$ & $122.69 \pm 6.86^{\mathrm{C}^{\mathrm{b} 3}}$ & 0.001 \\
Group 4:(2.2 ml/100g/day) & & $128.57 \pm 6.83^{\mathrm{c}^{\mathrm{d} 2}}$ & $190.62 \pm 3.61^{\mathrm{d} 3}$ & 0.001 \\
P-value $^{1.00}$ & 0.001 & 0.001 &
\end{tabular}

Data are expressed as mean $\pm S E(n=15)$; mean values with different alphabet superscripts within a colum $n$ differ significantly $(p<0.05)$; mean values not sharing a superscript digit in a row indicate significant difference at $p$ $<0.05$

Table 2: Serum ALT (U/L) levels of rats treated daily by different concentrations of energy drinks for 12 weeks

\begin{tabular}{lcccc}
\hline \multirow{2}{*}{ Group } & \multicolumn{3}{c}{ Duration of consumption } & \multirow{2}{*}{$\boldsymbol{P}$-value } \\
\cline { 2 - 4 } & Initial & Half-way (6 weeks) & End (12 weeks) & \\
\hline Group 1:(control) & & $54.27 \pm 4.62^{\mathrm{aL}}$ & $58.92 \pm 3.99^{\mathrm{a} 2}$ & 0.04 \\
Group 2:(0.4 ml/100g/day) & $45.27 \pm 2.47^{1}$ & $59.09 \pm 2.66^{\mathrm{a} 2}$ & $66.27 \pm 3.45^{\mathrm{a} 2}$ & 0.001 \\
Group 3:(1.1 ml/100g/day) & & $61.94 \pm 4.23^{\mathrm{a} 2}$ & $69.13 \pm 4.39^{\mathrm{a} 2}$ & 0.001 \\
Group 4:(2.2 ml/100g/day) & & $90.79 \pm 6.73^{\mathrm{b} 2}$ & $107.80 \pm 7.90^{\mathrm{b} 2}$ & 0.001 \\
P-value & 1.00 & 0.001 & 0.001 &
\end{tabular}

Data are expressed as mean $\pm S E \quad(n=15)$; mean values with different alphabet superscripts within a column differ significantly $(p<0.05)$; mean values not sharing a superscript digit in a row indicate significant difference at $p$ $<0.05$ 
Table 3: Serum ALP (U/L) levels of rats treated daily by different concentrations of energy drinks for 12 weeks

\begin{tabular}{lcccc}
\hline \multirow{2}{*}{ Group } & \multicolumn{3}{c}{ Duration of consumption } & \multirow{2}{*}{$\boldsymbol{P}$-value } \\
\cline { 2 - 4 } & Initial & Half-way (6 weeks) & End (12 weeks) & 0.91 \\
\hline Group 1:(control) & & $142.40 \pm 11.37^{\mathrm{al}}$ & $133.69 \pm 8.71^{\mathrm{a} 1}$ & 0.06 \\
Group 2:(0.4 ml/100g/day) & $137.27 \pm 18.20^{1}$ & $158.64 \pm 9.16^{\mathrm{ab} 1}$ & $182.64 \pm 9.16^{\mathrm{b} 1}$ & 0.001 \\
Group 3:(1.1 ml/100g/day) & & $200.29 \pm 11.62^{\mathrm{b} 2}$ & $237.00 \pm 12.41^{\mathrm{c} 2}$ & 0.001 \\
Group 4:(2.2 ml/100g/day) & & $300.86 \pm 15.70^{\mathrm{c} 2}$ & $421.69 \pm 18.25^{\mathrm{d} 3}$ & 0.001 \\
P-value & 1.00 & 0.001 & &
\end{tabular}

Data are expressed as mean $\pm S E(n=15)$; mean values with different alphabet superscripts within a column differ significantly $(p<0.05)$; mean values not sharing a superscript digit in a row indicate significant difference at $p$ $<0.05$

Table 4: Serum creatinine (mg/dL) levels of rats treated daily by different concentrations of energy drinks for 12 weeks

\begin{tabular}{lcccc}
\hline \multirow{2}{*}{ Group } & \multicolumn{3}{c}{ Duration of consumption } & \multirow{2}{*}{$\boldsymbol{P}$-value } \\
\cline { 2 - 4 } & Initial & Half-way (6 weeks) & End (12 weeks) & \\
\hline Group 1:(control) & & $0.43 \pm 0.03^{\mathrm{a} 12}$ & $0.45 \pm 0.03^{\mathrm{ac}}$ & 0.02 \\
Group 2:(0.4 ml/100g/day) & $0.33 \pm 0.02^{1}$ & $0.45 \pm 0.02^{\mathrm{a} 2}$ & $0.53 \pm 0.02^{\mathrm{ab} 2}$ & 0.001 \\
Group 3:(1.1 ml/100g/day) & $0.47 \pm 0.02^{\mathrm{ab} 2}$ & $0.58 \pm 0.05^{\mathrm{b} 2}$ & 0.001 \\
Group 4:(2.2 ml/100g/day) & & $0.57 \pm 0.04^{\mathrm{b} 2}$ & $0.73 \pm 0.03^{\mathrm{c} 3}$ & 0.001 \\
P-value & 1.00 & 0.001 & 0.001 &
\end{tabular}

Data are expressed as mean \pm SE $(n=15)$; mean values with different alphabet superscripts within a column differ significantly $(p<0.05)$; mean values not sharing a superscript digit in a row indicate significant difference at $p$ $<0.05$

Table 5: Blood urea nitrogen $(\mathrm{mg} / \mathrm{dL})$ levels of rats treated daily by different concentrations of energy drinks for 12 weeks

\begin{tabular}{lcccc}
\hline \multirow{2}{*}{ Group } & \multicolumn{4}{c}{ Duration of consumption } \\
\cline { 2 - 4 } & Initial & Half-way (6 weeks) & End (12 weeks) & P-value \\
\hline Group 1:(control) & & $10.23 \pm 0.33^{\mathrm{a} 2}$ & $8.68 \pm 0.44^{\mathrm{a} 22}$ & 0.84 \\
Group 2:(0.4 ml/100g/day) & $7.57 \pm 0.55^{1}$ & $10.60 \pm 0.48^{\mathrm{a} 2}$ & $11.54 \pm 0.48^{\mathrm{b} 2}$ & 0.001 \\
Group 3:(1.1 ml/100g/day) & & $18.70 \pm 0.60^{\mathrm{b} 2}$ & $19.79 \pm 0.64^{\mathrm{c} 2}$ & 0.001 \\
Group 4:(2.2 ml/100g/day) & 1.00 & $17.41 \pm 0.59^{\mathrm{b} 2}$ & $23.48 \pm 0.63^{\mathrm{d} 3}$ & 0.001 \\
P-value & & 0.001 & 0.001 & \\
\hline
\end{tabular}

Data are expressed as mean $\pm S E \quad(n=15)$; mean values with different alphabet superscripts within a column differ significantly $(p<0.05)$; mean values not sharing a superscript digit in a row indicate significant difference at $p$ $<0.05$

Table 6: Serum uric acid (mg/dl) levels of rats treated daily by different concentrations of energy drinks for 12 weeks

\begin{tabular}{lcccc}
\hline \multirow{2}{*}{ Group } & \multicolumn{3}{c}{ Duration of consumption } & \multirow{2}{*}{$\boldsymbol{P}$-value } \\
\cline { 2 - 4 } & Initial & Half-way (6 weeks) & End (12 weeks) & \\
\hline Group 1:(control) & & $2.41 \pm 0.21^{\mathrm{a} 2}$ & $2.31 \pm 0.19^{\mathrm{a} i}$ & 0.84 \\
Group 2:(0.4 ml/100g/day) & $2.37 \pm 0.10^{1}$ & $2.57 \pm 0.10^{\mathrm{a} 2}$ & $2.71 \pm 0.11^{\mathrm{b} 3}$ & 0.001 \\
Group 3:(1.1 ml/100g/day) & $3.07 \pm 0.12^{\mathrm{b} 2}$ & $3.28 \pm 0.13^{\mathrm{c} 2}$ & 0.001 \\
Group 4:(2.2 ml/100g/day) & & $3.46 \pm 0.15^{\mathrm{b} 2}$ & $3.89 \pm 0.16^{\mathrm{a} 3}$ & 0.001 \\
P-value & 1.00 & 0.001 & 0.001 &
\end{tabular}

Data are expressed as mean \pm SE $(n=15)$; mean values with different alphabet superscripts within a column differ significantly $(p<0.05)$; mean values not sharing a superscript digit in a row indicate significant difference at $p$ $<0.05$ 
Table 7: Superoxide dismutase (SODs, units $/ \mathrm{mL}$ ) level in erythrocytes of male rats orally and daily administrated different concentration of energy drinks for 12 weeks

\begin{tabular}{|c|c|c|c|c|}
\hline \multirow[b]{2}{*}{ Group } & \multicolumn{3}{|c|}{ Duration of consumption } & \multirow{2}{*}{$P$-value } \\
\hline & Initial & Half-way (6 weeks) & End (12 weeks) & \\
\hline Group 1:(control) & & $0.22 \pm 0.02^{\mathrm{a} 1}$ & $0.23 \pm 0.02^{\mathrm{a} 1}$ & 0.75 \\
\hline Group 2:(0.4 ml/100g/day) & $020+002^{1}$ & $0.21 \pm 0.02^{\mathrm{a} 1}$ & $0.21 \pm 0.02^{\mathrm{a} 1}$ & 0.99 \\
\hline Group 3:(1.1 ml/100g/day) & $0.20 \pm 0.02$ & $0.20 \pm 0.01^{\mathrm{a} 1}$ & $0.19 \pm 0.01^{\mathrm{a} 1}$ & 0.77 \\
\hline Group 4:(2.2 ml/100g/day) & & $0.17 \pm 0.01^{\mathrm{a} 1}$ & $0.09 \pm 0.01^{\mathrm{b} 2}$ & 0.001 \\
\hline$P$-value & 1.00 & 0.26 & 0.001 & \\
\hline
\end{tabular}

Data are expressed as mean $\pm S E(n=15)$; mean values with different alphabet superscripts within a column differ significantly $(p<0.05)$; mean values not sharing a superscript digit in a row indicate significant difference at $p$ $<0.05$

Table 8: Glutathione Peroxidase $(\mathrm{nmol} / \mathrm{min} / \mathrm{mL})$ level in erythrocyte of rats treated daily by different concentrations of energy drinks for 12 weeks

\begin{tabular}{lcccc}
\hline \multirow{2}{*}{ Group } & \multicolumn{3}{c}{ Duration of consumption } & \multirow{2}{*}{$\boldsymbol{P}$-value } \\
\cline { 2 - 4 } & Initial & Half-way (6 weeks) & End (12 weeks) & \\
\hline Group 1:(control) & & $78.91 \pm 2.08^{\mathrm{al}}$ & $77.30 \pm 1.45^{\mathrm{al}}$ & 0.47 \\
Group 2:(0.4 ml/100g/day) & $80.30 \pm 1.45^{1}$ & $76.07 \pm 1.98^{\mathrm{a} 12}$ & $73.92 \pm 0.85^{\mathrm{a} 2}$ & 0.02 \\
Group 3:(1.1 ml/100g/day) & & $56.31 \pm 3.19^{\mathrm{b} 2}$ & $53.40 \pm 3.19^{\mathrm{b} 2}$ & 0.001 \\
Group 4:(2.2 ml/100g/day) & & $45.86 \pm 2.49^{\mathrm{c} 2}$ & $42.69 \pm 2.41^{\mathrm{c} 2}$ & 0.001 \\
$P_{\text {-value }}$ & 1.00 & 0.001 & 0.001 & \\
\hline
\end{tabular}

Data are expressed as mean $\pm S E(n=15)$; mean values with different alphabet superscripts within a column differ significantly $(p<0.05)$; mean values not sharing a superscript digit in a row indicate significant difference at $p$ $<0.05$

Table 9: Plasma catalase $(\mathrm{nmol} / \mathrm{min} / \mathrm{mL})$ level of rats treated daily by different concentrations of energy drinks for 12 weeks

\begin{tabular}{|c|c|c|c|c|}
\hline \multirow{2}{*}{ Group } & \multicolumn{3}{|c|}{ Duration of consumption } & \multirow{2}{*}{$P$-value } \\
\hline & Initial & Half-way (6 weeks) & End (12 weeks) & \\
\hline Group 1:(control) & & $15.69 \pm 1.40^{\mathrm{a} 1}$ & $14.82 \pm 1.37^{\mathrm{a} 1}$ & 0.86 \\
\hline Group 2:(0.4 ml/100g/day) & $1178+1+18^{1}$ & $14.46 \pm 1.31^{\mathrm{a} 1}$ & $13.20 \pm 0.99^{\mathrm{a} 1}$ & 0.61 \\
\hline Group 3:(1.1 ml/100g/day) & $14 . / 8 \pm 1.18$ & $13.96 \pm 1.28^{\mathrm{a} 1}$ & $12.97 \pm 1.29^{\mathrm{a} 1}$ & 0.60 \\
\hline Group 4:(2.2 ml/100g/day) & & $12.74 \pm 0.83^{\mathrm{a} 12}$ & $10.17 \pm 0.73^{\mathrm{a} 2}$ & 0.01 \\
\hline$P$-value & 1.00 & 0.45 & 0.07 & \\
\hline
\end{tabular}

Data are expressed as mean \pm SE ( $n=15)$; mean values with different alphabet superscripts within a column differ significantly $(p<0.05)$; mean values not sharing a superscript digit in a row indicate significant difference at $p<0.05$

Marked dilatation and congestion of veins and severe inflammation of the interstitial as shown in Figure $1 \mathrm{III}$. Remnants of destroyed tubules were seen within areas of inflammation with signs of degeneration, necrosis, loss of cellular details and cell boundaries as shown in Figure 1 IV.

\section{DISCUSSION}

This study has demonstrated that oral administration of ED to rats for 12 weeks resulted in varying degrees of liver and kidney damage. This was evident in the ED-induced significant elevations in serum AST, ALT and ALP, creatinine, BUN and uric acid levels. Increases in the blood levels of hepatic enzymes serve as reliable indicators of liver damage by toxic agents. Similar increases have been reported in serum AST, ALT and ALP of rats exposed to caffeinated EDs [11]. It has been demonstrated that rats administered ED alone or in combination with alcohol showed higher serum total bilirubin, ALT, ALP and AST than untreated controls [12].

In the present study, serum uric acid and creatinine concentrations were significantly increased in ED-treated rats. Increases in blood levels of uric acid and creatinine are usually associated with impaired kidney function [13]. These results are in agreement with the findings of Khayyat and his colleagues who reported that EDs induced elevations in serum urea, uric acid and creatinine [14]. These researchers suggested that caffeine induced the elevations in urea, uric acid and creatinine through inhibition of A2A adenosine receptors, resulting in the development of interstitial inflammation, increased proteinuria and deleterious changes in renal function and structure [14]. 


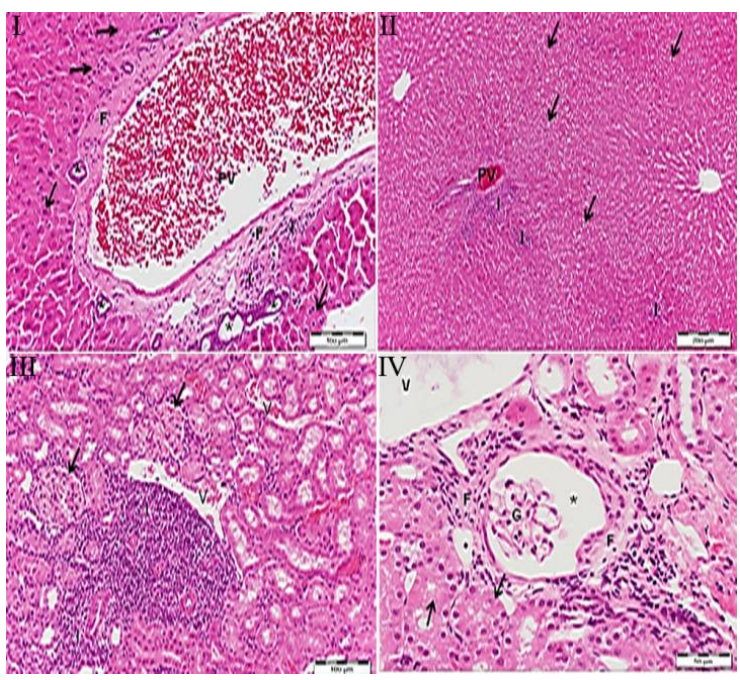

Figure 1: Light micrographs of liver (I and II) and kidney (III and IV) sections of rat in G 4 (highest EDexposed group). Specimens were fixed in $10 \%$ neutral formalin and stained with $H$ \& $E$, magnification $100 \mu \mathrm{m}$. I: Showing a markedly dilated and congested portal vein (PV). The portal area shows starting fibrosis (F), inflammatory cellular infiltration (I), and bile duct proliferation (asterisks). Hepatocytes at the periphery of the lobules show undergoing degeneration and necrosis with shrunken or disappearing nuclei (arrows). II: Showing distorted general architecture of the liver, congestion of a portal vein (PV) and inflammation (I) in portal areas as well as between hepatocytes which also show marked vacuolation mainly at the peripheries of lobules (arrows). III: Showing distorted general architecture, marked dilatation and congestion of veins (V) and severe inflammation of the interstitial tissue (I). Some renal corpuscles are reduced in size with narrowing of the urinary space (arrows). IV: Showing a markedly dilated vein (V), a renal corpuscle with a markedly shrunken glomerulus (G) and a markedly widened urinary space (asterisk). The renal corpuscle is surrounded by starting Fibrosis $(F)$. The tubular cells show signs of degeneration and necrosis with loss of cellular details and cell boundaries (arrows)

However, some other ED-based studies reported findings that are at variance with these results. For example, it has been reported that consumption of EDs was associated with higher plasma total protein and lowered levels of creatinine, albumin and uric acid [16]. Yet other researchers found no significant association between caffeine intake and the serum levels of urea and creatinine in rats [17]. These disparities on the effect of ED may be attributed to lack of uniformity in the composition of these energy beverages.

The present study also revealed that ED exposure led to increased oxidative stress in the rats. This was evident in the ED-induced significant decreases in activities of SOD, CAT and GPx. These enzymes are important antioxidants which work in concert with the nonenzymatic antioxidant system to protect cells from oxidative damage by free radicals [18]. Indeed, the antioxidant enzymes are the first line of defense which protects cells from oxidative stress-induced damage. Superoxide dismutase (SOD) neutralizes the highly reactive superoxide anion by converting it to hydrogen peroxide, which is in turn degraded to water by GPx and CAT [19]. The significant reductions in blood levels of these enzymes, especially in the rats that received medium and high doses of ED, might be due to ED-induced increases in superoxide radical, thereby overwhelming the neutralizing capacities of the antioxidant enzymes.

Studies have shown that exposure of human cells to high levels of caffeine induced a prooxidant environment in the cells, leading to increased protein oxidation, while low levels of caffeine had no effect on the antioxidant capacity of cells [20]. It has been demonstrated that caffeine significantly increased BUN levels, resulting in the activation of xanthine oxidase which in turn, stimulated the oxidation of xanthine to uric acid, and generation of superoxide anion and $\mathrm{H}_{2} \mathrm{O}_{2}$ [21]. The interaction between $\mathrm{H}_{2} \mathrm{O}_{2}$ with $\mathrm{O} 2$ produces free radicals. On the other hand, several studies have independently demonstrated the antioxidant properties of many components of ED such as taurine, ginseng, caffeine and guarana [21].

The pattern of variations seen in liver and kidney function parameters of rats exposed to the different doses of ED was in agreement with the lesions in the photomicrographs of these tissues. The observed lesions are most likely a consequence of the deleterious effects of ED. It can be reasonably suggested that the lesions were brought about by tissue damage arising from ED-induced oxidative stress. These results are consistent with a previous report on evidence of hepatotoxicity and alterations in liver ultrastructure in rats treated with different types of EDs [22]. In another study, the lesions in liver and kidney tissues were attributed to potential reaction of taurine with some other active ED ingredient such as caffeine [23]. In addition, Khayyat and his colleagues found that rats treated with EDs had hepatic cytoplasmic vacuolations due to presence of lipid droplets which were attributed to deteriorative changes within hepatocytes [22].

Many investigators are in agreement on the adverse effects of ED as obtained in the present 
study [11]. However, others reported that Power Horse and Red Bull significantly influenced liver enzyme activities but had no significant influence liver histopathology [16]. Some researchers reported irregular outlines and pyknosis in the nuclei of hepatocytes, and numerous mitotic figures [17]. These changes may be attributed to the toxic effects of caffeine, and the harmful effects of preservative substances added to EDs, such as sodium benzoate [24]. However, it has been reported that ED-induced hepatocyte damage was reversible as indicated by blood chemistry analysis and histopathological studies of the organs of animals in the recovery group [19].

\section{CONCLUSION}

The results of this study demonstrate that exposure of rats to high doses of Red bull for 12 weeks leads to liver and kidney damage. The pronounced reduction in the blood levels of key antioxidant enzymes suggests that the harmful effects of Red bull are mediated through increased ROS generation and oxidative stress. If animal-to-man extrapolation is permitted, these results call for restraint and caution in the consumption of Red bull and other EDs. Thus, the need for adequate public awareness cannot be over-emphasized.

\section{DECLARATIONS}

\section{Acknowledgement}

The authors greatly appreciate the efforts of Dr Mohammad Atteya, Assistant Professor of Histology, Anatomy Department, College of Medicine, King Saud University in preparing, interpreting and writing reports for the histopathological aspects of this work.

\section{Conflict of Interest}

No conflict of interest is associated with this work.

\section{Contribution of Authors}

We declare that this work was done by the authors named in this article and all liabilities pertaining to claims relating to the content of this article will be borne by the authors. Mansy and Hanafi designed the study and drafted the manuscript, Alogaiel participated in the whole experimental work and statistical analysis. Zakaria, Alogaiel and Mansy critically reviewed the manuscript. All authors read and approved the final manuscript.

\section{REFERENCES}

1. Reissig C, Strain EC, Griffiths RR. Caffeinated energy drinks a growing problem. Drug Alcohol Depend 2009; 99: 1-10.

2. Elsoadaa S, Hejazi H, Sonbul A, Fayyadhah S, Al-Ahdal S, Al-Turkistani S, Zarad R, AL- Harithy M. Prevalence of Energy Drinks Consumption among Adolescents and Young Adults in Makkah, KSA. J Health Med Nursing 2016; 33: 79-90.

3. Seifert SM, Schaechter JL, Hershorin ER, Lipshultz SE. Health effects of energy drinks on children, adolescents, and young adults. Pediatrics 2011; 127: 511-528

4. Tanne JH. New York attorney general investigates energy drink makers. BMJ 2012; 345: e6108.

5. Burrows $T$, Pursey $K$, Neve M, Stanwell P. What are the health implications associated with the consumption of energy drinks? A systematic review. Nutr Rev 2013; 71: 135-148

6. Ali F, Rehman H, Babayan Z, Stapleton D. \& Divya-Devi J. Energy drinks and their adverse health effects: a systematic review of the current evidence. Postgrad Med J 2015; 127(3): 308-322

7. National Research Council. 2011. Guide for the Care and Use of Laboratory Animals: Eighth Edition. Washington, DC: The National Academies

8. Bergmeyer HV, Methods of Enzymatic analysis. Weinheim Verlag Chemie 1984; 3: 92.

9. Aly NM, Abou-El-khear RK, El-Bakary AS. Immunological, haematological studies on albino rats treated with warfarin. Alex Sci Exch J 1997; 18: 265275.

10. Seven A, Guzel S, Seymen O, Civelek S, Bolayirli M, Uncu $M$, Burcak $G$. Effects of vitamin E supplementation on oxidative stress in streptozotocin induced diabetic rats: investigation of liver and plasma. Yonsei Med $\mathrm{J}$ 2004; 45: 703-710.

11. Bukhari HM, El-Sawy NA, Header EA. Biological Effect of High Energy Drink on Normal and Hyperglycemic Rats. Pak J Nut 2012; 11(4): 301-309.

12. Ugwuja El. Biochemical Effects of Energy Drinks Alone or in Combination with Alcohol in Normal Albino Rats. Adv Pharm Bull 2014; 4(1): 69-74.

13. Mossa AH \& Abbassy MA, Adverse haematological and biochemical effects of certain formulated insecticides in male rats. Res J Environ Toxicol 2012; 6: 160-168.

14. Khayyat L, Essawy A, Sorour J, Al Rawi M. Impact of Some Energy Drinks on the Structure and Function of the Kidney in Wistar Albino Rats. Life Sci J 2014; 11(10): 1131-1138.

15. Tofovic S, Kost C, Jackson E, Bastacky A. Long term caffeine consumption exacerbates renal failure in obese, diabetic, ZSF1(fa-fa) rats. Kidney Int 2002; 61: 14331444.

16. Ebuehi OA, Ajayl OE, Onyeulor AL, Awelimobor $D$. Effects of oral administration of energy drinks on blood chemistry, tissue histology and brain acetylcholine in rabbits. Nig Q J Hosp Med 2011; 21(1):29-34. 
17. Akande IS, Banjoko O A. Assessment of Biochemical Effect of "Power Horse" Energy Drink on Hepatic, Renal and Histological Functions in Sprague Dawley Rats. Annu Res Rev Biol 2011; 1(3): 45-56.

18. Abdollahi M, Ranjbar A, Shadnia S, Nikfar S, Rezaie A. Pesticides and oxidative stress: a review. Med Sci Monit 2004; 10: 141-147.

19. Sharma D, Sangha GK. Triazophos induced oxidative stress and histomorphological changes in liver and kidney of female albino rats. Pestic Biochem Physiol 2014; 110: 71-80.

20. Dias TR, Alves MG, Bernardino RL, Martins $A D$, Moreira $A C$, Silva J, Barros A, Sousa M, Silva BM, Oliveira PF. Dose-dependent effects of caffeine in human Sertoli cells metabolism and oxidative profile: Relevance for male fertility. Toxicology 2015; 328: 12-20.
21. Obochi GO, Amali OE, Ochalefu DO. Effect of Melatonin and Caffeine Interaction on Caffeine Induced Oxidative Stress and Sleep Disorders. Nig J Physiol Sci 2010; 25: 17-24.

22. Khayyat L, Sorour J, Al Rawi M, Essawy A. Histological, Ultrastructural and Physiological Studies on the Effect of Different Kinds of Energy Drinks on the Liver of Wistar albino Rat. Am Sci J 2012; 8(8): 688-697.

23. Berger AJ \& Alford K. Cardiac arrest in a young man following excess consumption of caffeinated energy drinks. Med J Aust 2009; 190: 41-43.

24. Mubarak R. Effect of Red Bull energy drink on Rats' Submandibular salivary glands (Light and Electron microscopic Study). J Am Sci; 2012; 8(1): 366-372. 